\title{
Population distributions from native mass spectrometry titrations reveal nearest-neighbor cooperativity in the ring-shaped oligomeric protein TRAP
}

Melody L. Holmquist,' Elihu C. Ihms, ${ }^{2}$ Paul Gollnick, ${ }^{, V i c k i}$ H. Wysocki*,, and Mark P. Foster*,,A

Department of Chemistry and Biochemistry, The Ohio State University, Columbus, Ohio

2VPPL, Vaccine Research Center, NIAID, NIH, Vaccine Pilot Plant (VPP), Frederick, Maryland

${ }^{3}$ Department of Biological Sciences, State University of New York at Buffalo, Buffalo, New York

${ }^{4}$ Resource for Native Mass Spectrometry Guided Structural Biology, The Ohio State University, Columbus, Ohio

Corresponding authors: $\underline{\text { foster.281@osu.edu; wysocki.11@osu.edu }}$

\section{Supplemental Information}

\section{Table of Contents}

Figure S1. Deconvolution and integration of populations of $\operatorname{Trp}_{n}: \operatorname{TRAP}_{\|}$states.................................S2

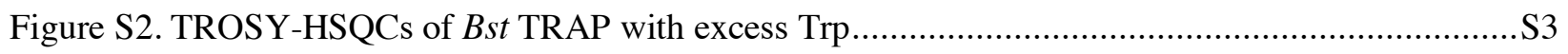

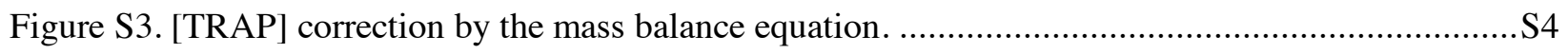

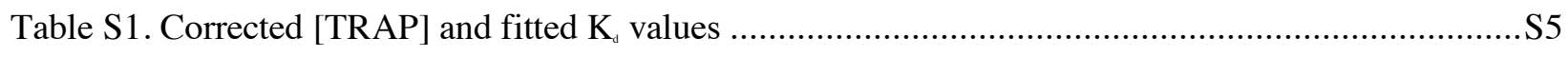

Figure S4. Coupling free energies of Trp binding to TRAP .......................................................... 6

Table S2. Best-fit parameters from the nearest neighbor model ..................................................S7

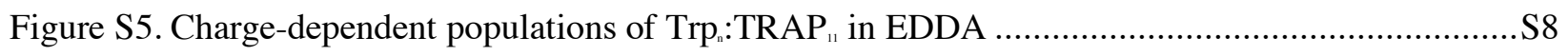

Table S3. Charge-dependent $\Delta \mathrm{G}$ and $\mathrm{K}_{\mathrm{d}}$ values of $\mathrm{Trp}$ binding to TRAP $\mathrm{P}_{\mathrm{il}}$ in EDDA............................S9

Figure S6. Charge-dependent populations of $\operatorname{Trp}_{\mathrm{n}}: \mathrm{TRAP}_{\mathrm{u}}$ in AmAc ...............................................S10

Table S4. Charge-dependent $\Delta \mathrm{G}$ and $\mathrm{K}_{\mathrm{d}}$ values of Trp binding to $\mathrm{TRAP}_{\mathrm{n}}$ in AmAc .......................... 111

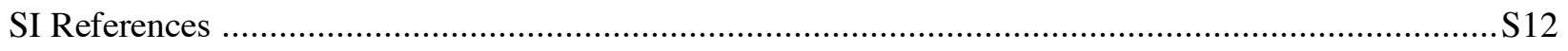



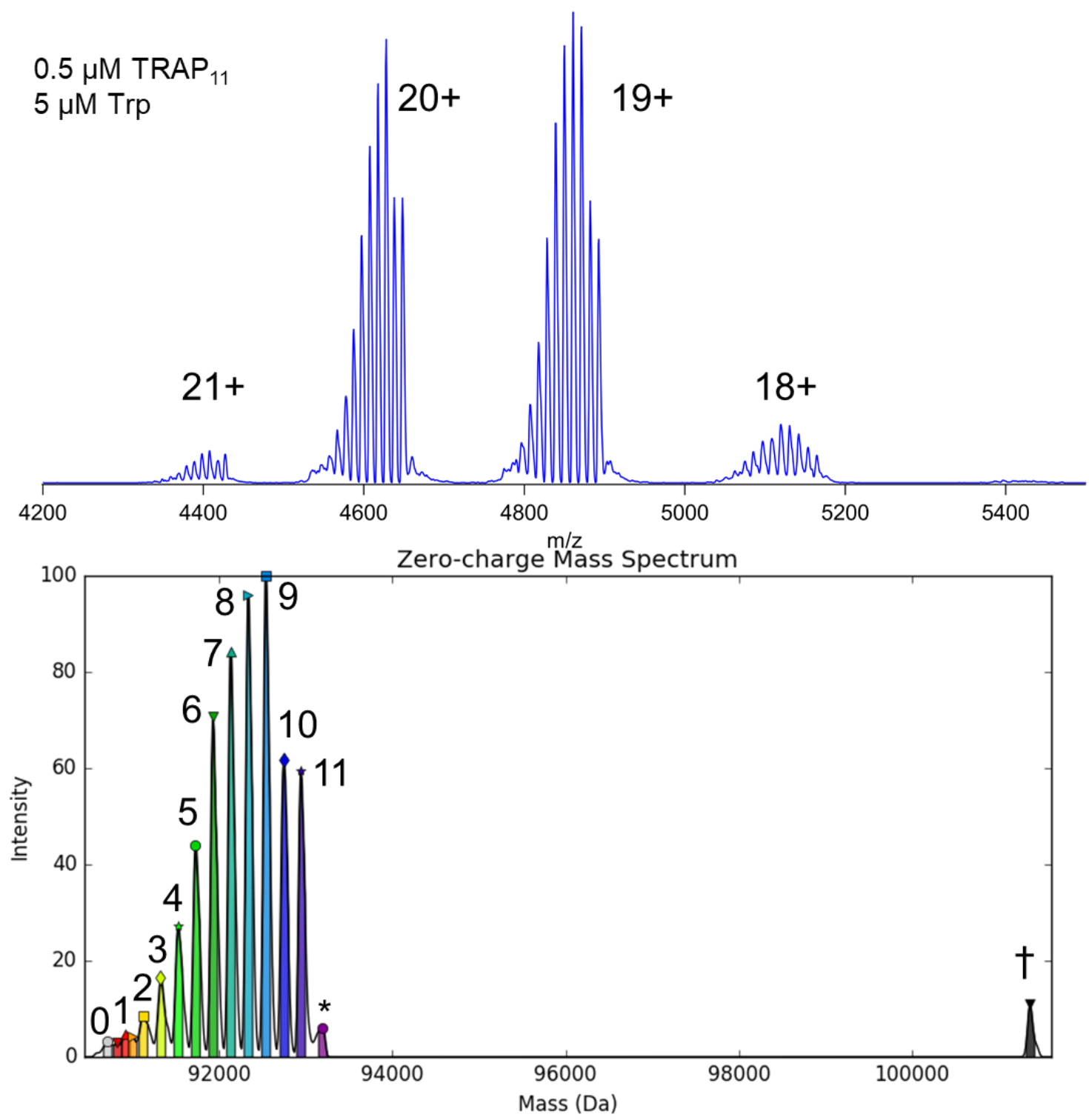

Figure S1. Populations of $\operatorname{Trp}_{\mathrm{n}}$ :TRAP ${ }$ states were obtained by deconvolution and integration. (Top) Representative mass spectrum of $0.5 \mu \mathrm{M}_{\text {TRAP }}$ in $200 \mathrm{mM}$ EDDA incubated with $5 \mu \mathrm{M}$ Trp; charge states are as indicated. (Bottom) Deconvolution of the spectrum using UniDec, ${ }^{\prime}$ with the number of bound Trp indicated; shaded regions were integrated to obtain populations corresponding to TRAP ${ }_{11}$ with 0-11 bound Trp. Minor species marked $*$ and $\dagger$ correspond to TRAP ${ }_{11}$ with an extra bound Trp, and to TRAP bound to 12 Trp, respectively; these were excluded from the thermodynamic analysis. 


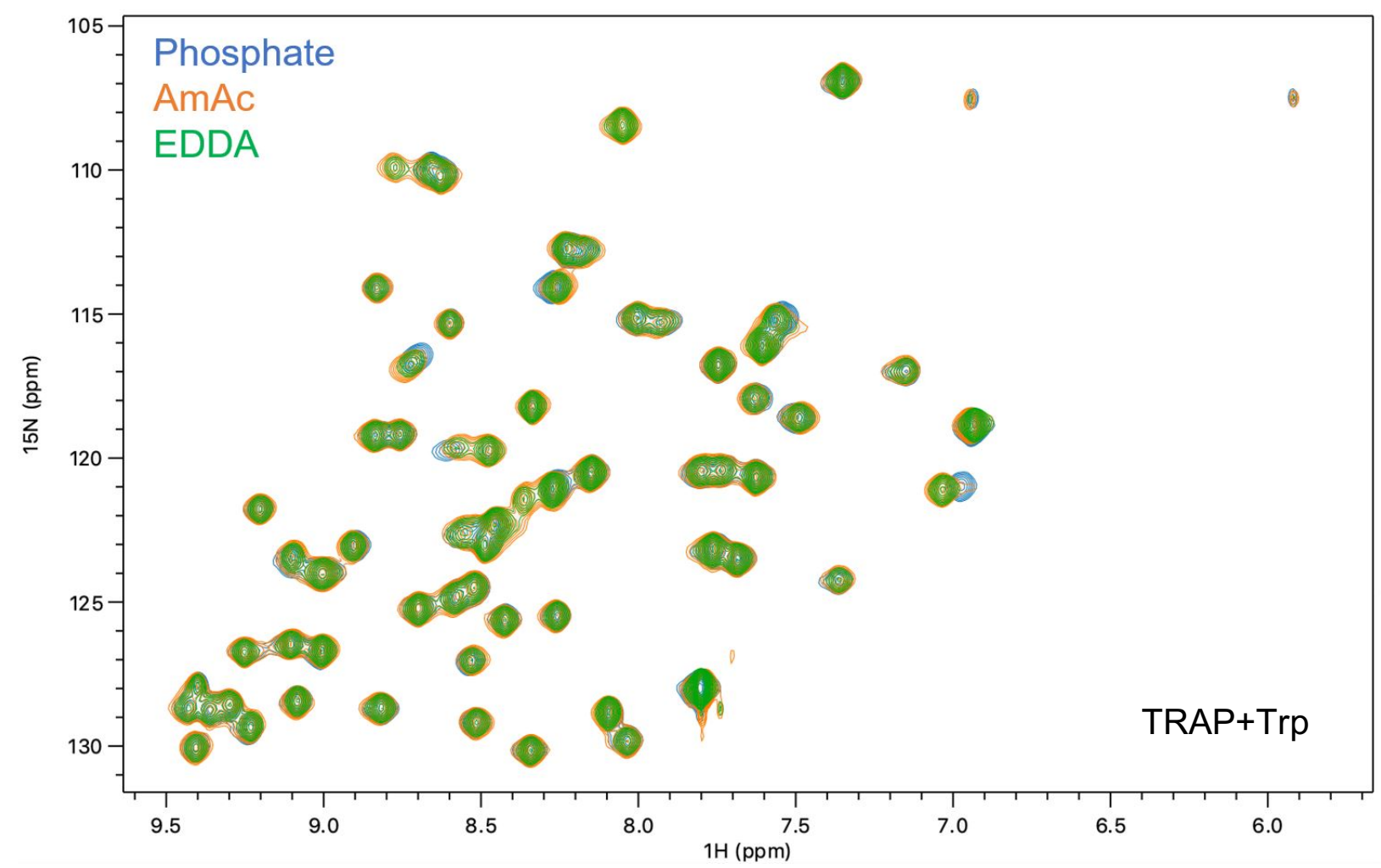

Figure S2. MS-compatible solutions induce minimal perturbations in the spectrum of Trp-bound TRAP. ${ }^{1} \mathrm{H}-{ }^{-1} \mathrm{~N}$ TROSY-HSQC spectra were recorded at $55^{\circ} \mathrm{C}$ on an $800 \mathrm{MHz}$ NMR spectrometer with a Bst TRAP monomer concentration of $\sim 1 \mathrm{mM}(0.09 \mathrm{mM}$ rings) and an excess of Trp. Solutions were: $50 \mathrm{mM}$ $\mathrm{NaPO}_{4}, 100 \mathrm{mM} \mathrm{NaCl}, \mathrm{pH} 8.0$ (blue); $100 \mathrm{mM}$ ammonium acetate, $\mathrm{pH} 8.0$ (orange); $100 \mathrm{mM}$ ethylenediamine diacetate, $\mathrm{pH} 8.0$ (green). 


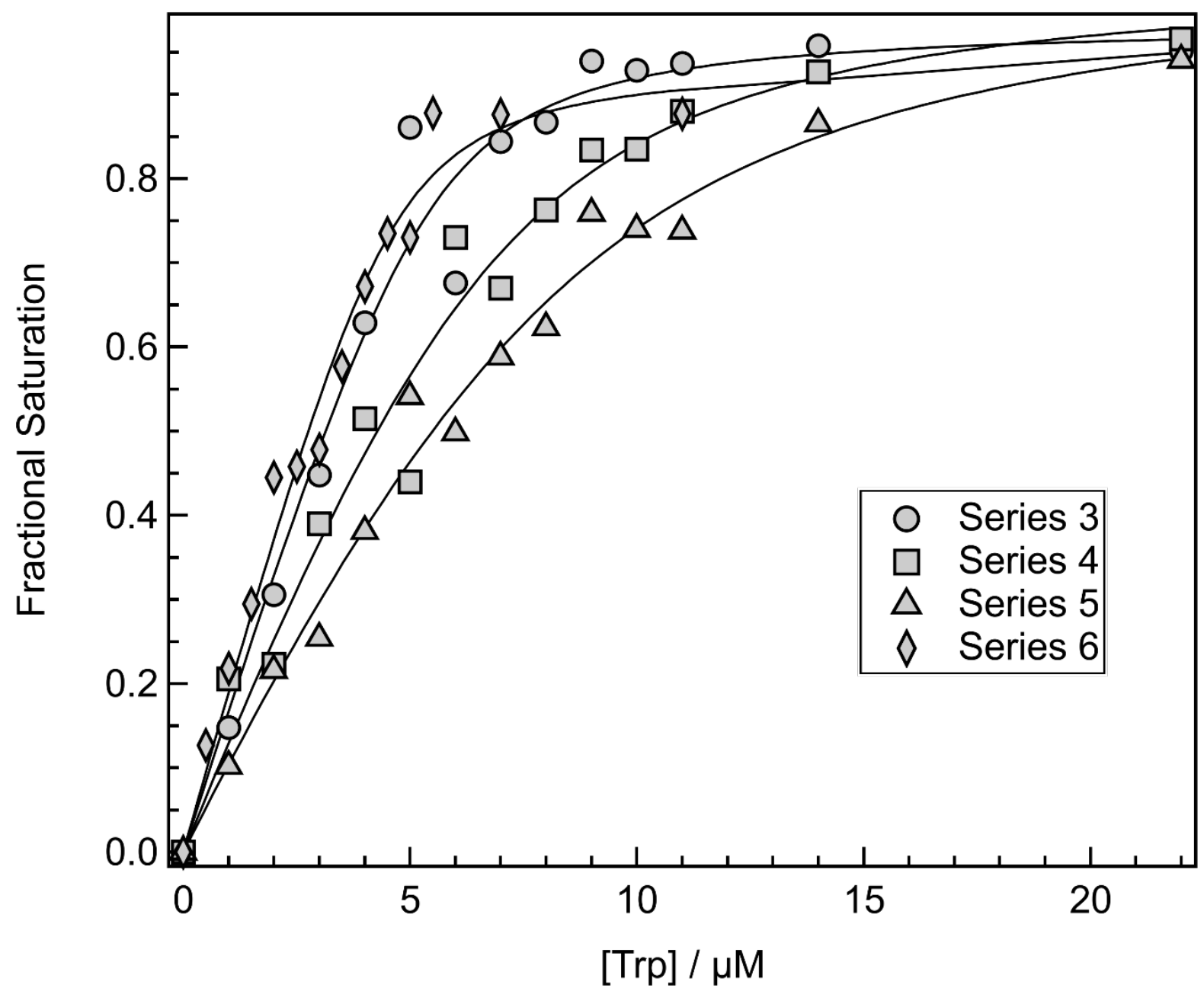

Figure S3. For each series representing a titration data set, binding site concentrations were corrected by fitting fractional saturation of all Trp sites using the mass balance equation for a 1 Trp: 1 site interaction. Representative data sets or series are shown here. The corrected [TRAP] and fitted $\mathrm{K}_{d}$ values for all series are listed in Table S1. 
Table S1. Corrected [TRAP] and $\mathrm{K}_{\mathrm{d}}$ values from mass balance equation fits using Dynafit. ${ }^{2}$

\begin{tabular}{ccccccc} 
& $\begin{array}{c}\text { Initial } \\
\text { Conc. } \\
(\boldsymbol{\mu} \mathbf{M})\end{array}$ & $\begin{array}{c}\text { Fitted Conc. } \\
(\boldsymbol{\mu} \mathbf{M})\end{array}$ & $\begin{array}{c}\% \\
\text { change }\end{array}$ & Std. Error & $\mathbf{K}_{\mathrm{d}}(\boldsymbol{\mu} \mathbf{M})$ & Std. Error \\
\hline Series 1 & 55 & 24.9 & 54.7 & 3.0 & 3.10 & 1.60 \\
\hline Series 2 & 55 & 46.3 & 15.8 & 3.2 & 0.38 & 0.68 \\
\hline Series 3 & 11 & 5.46 & 50.4 & 0.75 & 0.36 & 0.33 \\
\hline Series 4 & 11 & 6.8 & 38.2 & 1.3 & 1.11 & 0.92 \\
\hline Series 5 & 11 & 8.1 & 26.4 & 1.4 & 1.9 & 1.2 \\
\hline Series 6 & 5.5 & 4.63 & 15.8 & 0.41 & 0.27 & 0.22 \\
\hline
\end{tabular}




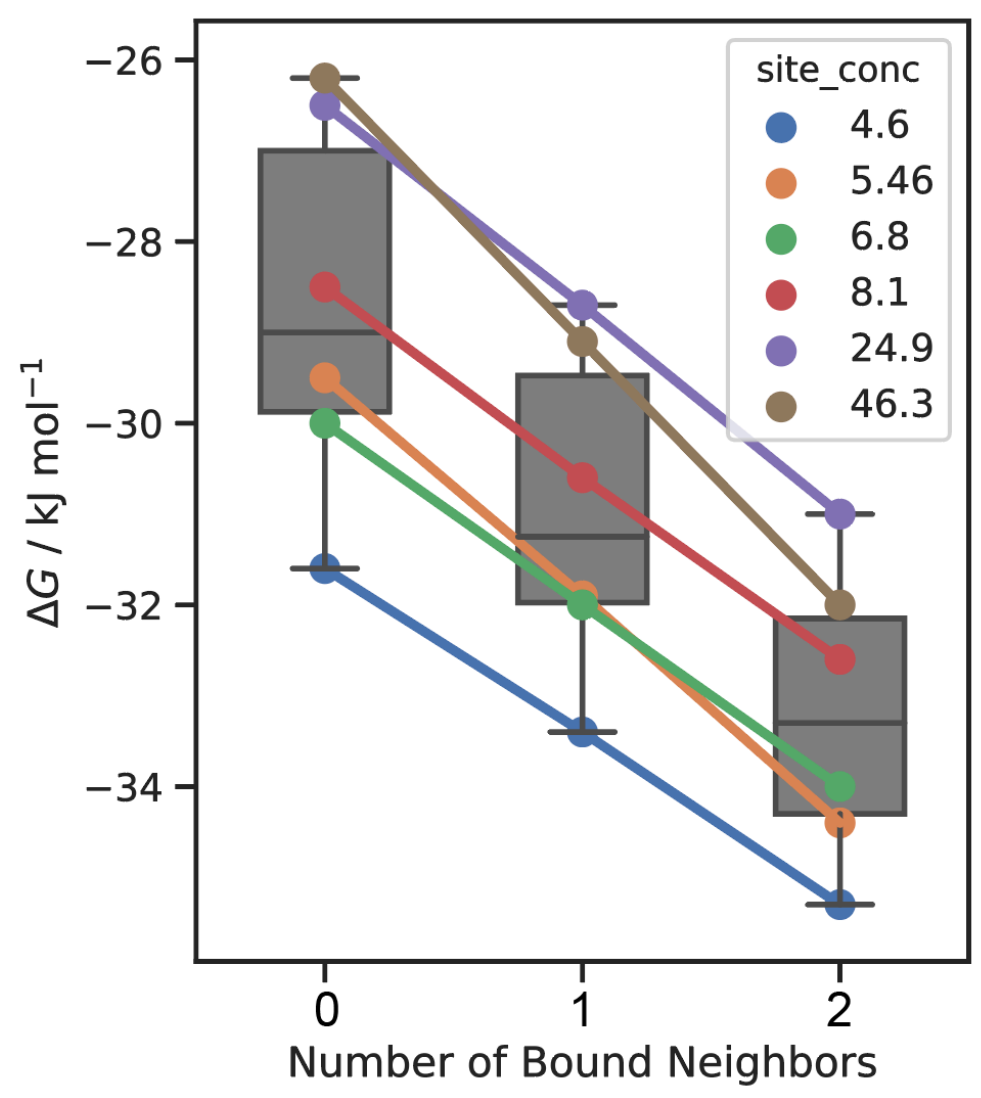

Figure S4. Affinity of Trp for TRAP exhibits modest concentration dependent behavior when sprayed from EDDA solutions. Best-fit parameters (Table S2) for fitting six independent data sets at the indicated binding site concentrations (in $10^{\circ} \mathrm{M}$; division by 11 gives TRAP ${ }^{\prime \prime}$ concentration) to sites with 0,1 or two occupied neighbors using the nearest-neighbor model. ${ }^{3}$ The highest and lowest concentrations correspond to data similar to Figures 3 and 4, respectively. 
Table S2. $\Delta \mathrm{G}$ and $\mathrm{K}_{4}$ values of Trp binding to TRAP from fitting titration data with the additive nearest neighbor binding model. [TRAP] is the concentration of TRAP protomers, not TRAP 11-mers.

\begin{tabular}{|c|c|c|c|c|c|c|c|}
\hline \multirow{2}{*}{\multicolumn{2}{|c|}{\begin{tabular}{c|c} 
& $\begin{array}{c}\text { [TRAP] } \\
\mu \mathrm{M}\end{array}$ \\
Bound Neighbors
\end{tabular}}} & \multicolumn{3}{|c|}{$\begin{array}{c}\Delta \mathrm{G} \text { values } \\
\mathrm{kcal} / \mathrm{mol}\end{array}$} & \multicolumn{3}{|c|}{$\begin{array}{c}\mathbf{K}_{\mathrm{d}} \text { values } \\
\boldsymbol{\mu} \mathbf{M}\end{array}$} \\
\hline & & \multirow{2}{*}{$\frac{\mathbf{0}}{-6.33}$} & \multirow{2}{*}{$\frac{1}{-6.86}$} & \multirow{2}{*}{$\frac{2}{-7.41}$} & \multirow{2}{*}{$\begin{array}{c}\mathbf{0} \\
22.93\end{array}$} & \multirow{2}{*}{$\frac{1}{9.30}$} & \multirow{2}{*}{$\frac{2}{3.77}$} \\
\hline Series1 & 24.9 & & & & & & \\
\hline Series2 & 46.3 & -6.26 & -6.96 & -7.65 & 25.32 & 7.89 & 2.46 \\
\hline Series3 & 5.46 & -7.05 & -7.62 & -8.22 & 6.76 & 2.55 & 0.96 \\
\hline Series4 & 6.8 & -7.17 & -7.65 & -8.13 & 5.58 & 2.50 & 1.12 \\
\hline Series5 & 8.1 & -6.81 & -7.31 & -7.79 & 10.28 & 4.44 & 1.92 \\
\hline Series6 & 4.63 & -7.55 & -7.98 & -8.44 & 2.90 & 1.38 & 0.66 \\
\hline \multicolumn{2}{|c|}{ Median } & -6.93 & -7.46 & -7.96 & 8.52 & 3.49 & 1.52 \\
\hline \multicolumn{2}{|c|}{ Mean } & -6.86 & -7.41 & -7.93 & 12.29 & 4.68 & 1.82 \\
\hline \multicolumn{2}{|c|}{ St. Deviation } & 0.50 & 0.43 & 0.38 & 9.50 & 3.22 & 1.17 \\
\hline
\end{tabular}



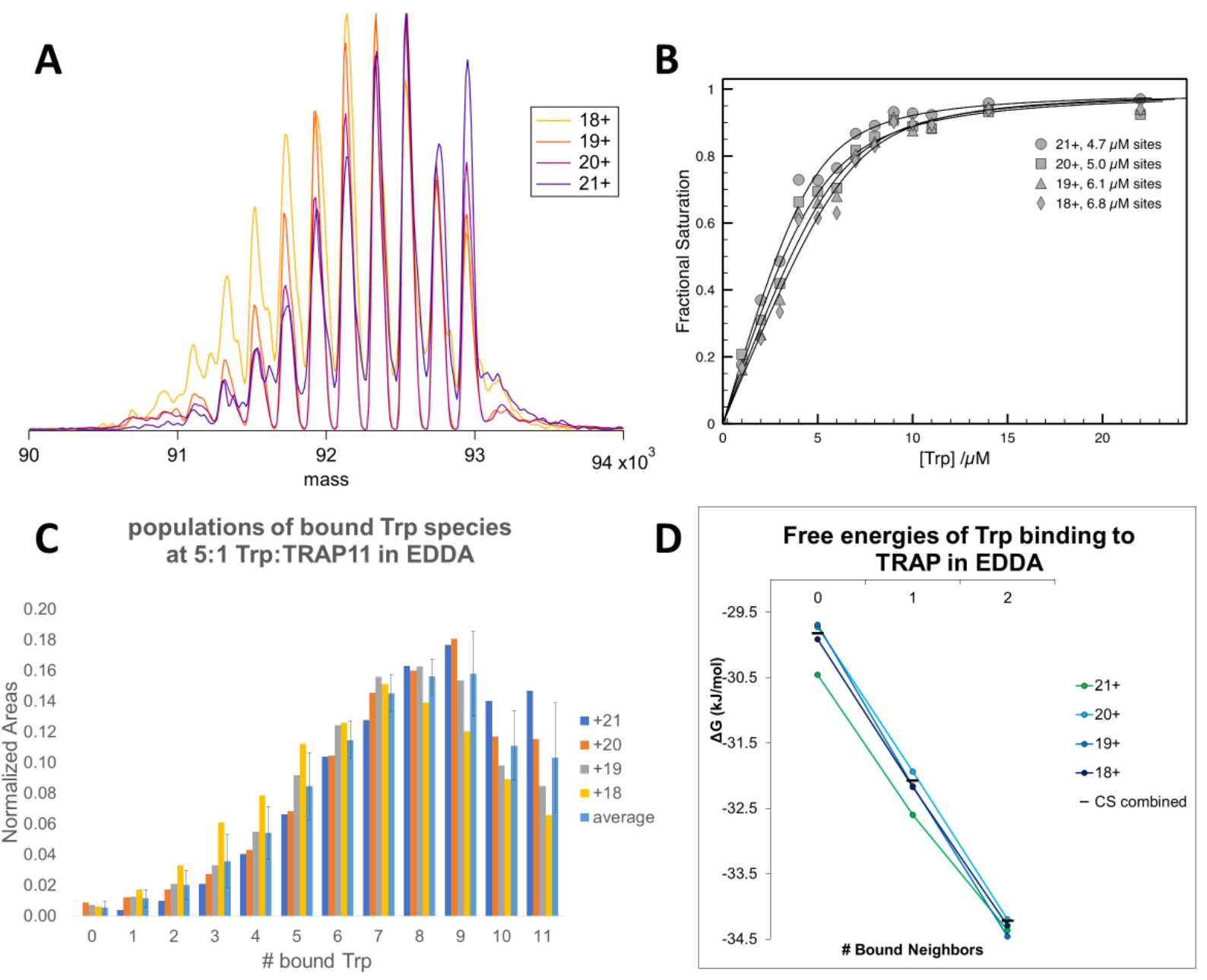

Figure S5. Trp ${ }_{n}-$ TRAP $_{\|}$populations vary slightly between charge states when sprayed from EDDA solutions. (A) Deconvoluted MS of four charge states (18+ to 21+) of $0.5 \mu \mathrm{M} B s t$ TRAP $_{n}$ in $5 \mu \mathrm{M}$ Trp, normalized to most intense signal for each charge state. (B) Concentration corrections of TRAP ${ }_{n}$ using mass balance equations. (C) $\operatorname{Trp}_{n}-\mathrm{TRAP}_{n}$ populations obtained from separate integration of signals from each of the four charge states; inset: charge state-specific concentration correction. (D) Best fits of populations for each charge state with the NN model yield slightly different thermodynamic parameters (Table S3). 
Table S3. $\Delta \mathrm{G}$ and $\mathrm{K}_{d}$ values of Trp binding to $\mathrm{TRAP}$ as a function of charge state from spectra in EDDA, obtained from fits to the NN model.

\begin{tabular}{c|ccc|ccc}
\hline Charge states & \multicolumn{4}{|c|}{$\boldsymbol{\Delta G}$ values $(\mathbf{k c a l} / \mathbf{m o l})$} & \multicolumn{3}{c}{$\mathbf{K}_{\mathrm{d}}$ values $(\boldsymbol{\mu} \mathbf{M})$} \\
\hline Bound Neighbors & $\mathbf{0}$ & $\mathbf{1}$ & $\mathbf{2}$ & $\mathbf{0}$ & $\mathbf{1}$ & $\mathbf{2}$ \\
\hline $\mathbf{2 1 +}$ & -7.28 & -7.79 & -8.21 & 4.61 & 1.94 & 0.95 \\
$\mathbf{2 0 +}$ & -7.11 & -7.63 & -8.17 & 6.20 & 2.54 & 1.02 \\
$\mathbf{1 9 +}$ & -7.10 & -7.69 & -8.24 & 6.28 & 2.32 & 0.92 \\
$\mathbf{1 8 +}$ & -7.15 & -7.69 & -8.20 & 5.74 & 2.30 & 0.98 \\
Combined (all CS) & -7.13 & -7.66 & -8.18 & 5.97 & 2.41 & 1.01 \\
\hline Average (C.S. 21 to 18) & -7.16 & -7.70 & -8.21 & 5.71 & 2.28 & 0.97 \\
\hline St. Deviation & 0.08 & 0.07 & 0.03 & 0.77 & 0.25 & 0.04
\end{tabular}



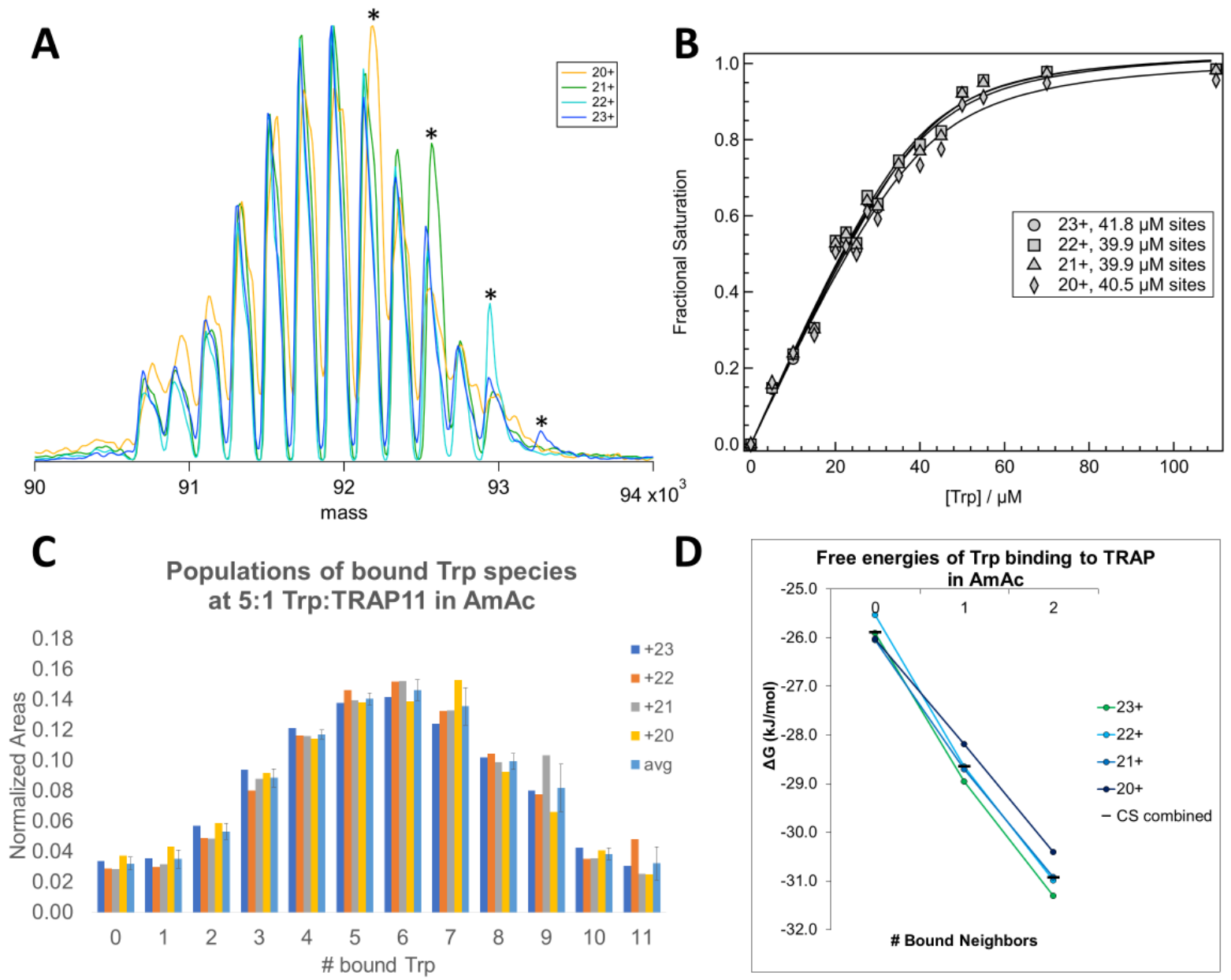

Figure S6. There is slight variation in $\operatorname{Trp}_{n}-\mathrm{TRAP}_{n}$ populations between charge states when sprayed from AmAc solutions. (A) Deconvoluted MS of four charge states (23+ to 20+) of $3.7 \mu \mathrm{M} B s t$ TRAP ${ }_{11}$ in 25 $\mu \mathrm{M}$ Trp, normalized to most intense signal for each charge state. Peaks with asterisks $(*)$ are $\operatorname{Trp}_{12}-\mathrm{TRAP}_{12}$ species overlapping with $\operatorname{Trp}_{n}-\mathrm{TRAP}_{n}$ species. (B) Concentration corrections of $\mathrm{TRAP}$ using mass balance equations. (C) $\operatorname{Trp}_{n}-\mathrm{TRAP}_{\text {n }}$ populations obtained from separate integration of signals from each of the four charge states; inset: charge state-specific concentration correction. (D) Best fits of populations for each charge state with the NN model yield slightly different thermodynamic parameters (Table S4). 
Table S4. $\Delta \mathrm{G}$ and $\mathrm{K}_{d}$ values of Trp binding to $\mathrm{TRAP}_{\|}$as a function of charge state from spectra in AmAc, obtained from fits to the NN model.

\begin{tabular}{|c|c|c|c|c|c|c|}
\hline Charge states & \multicolumn{3}{|c|}{$\Delta G$ values $(\mathrm{kcal} / \mathrm{mol})$} & \multicolumn{3}{|c|}{$\mathbf{K}_{\mathrm{d}}$ values $(\boldsymbol{\mu} \mathrm{M})$} \\
\hline Bound Neighbors & $\mathbf{0}$ & 1 & 2 & $\mathbf{0}$ & 1 & 2 \\
\hline $23+$ & -6.19 & -6.92 & -7.48 & 28.92 & 8.44 & 3.28 \\
\hline $22+$ & -6.10 & -6.85 & -7.41 & 33.58 & 9.55 & 3.72 \\
\hline $21+$ & -6.23 & -6.86 & -7.39 & 27.33 & 9.33 & 3.82 \\
\hline $20+$ & -6.22 & -6.74 & -7.27 & 27.51 & 11.52 & 4.70 \\
\hline Combined (all CS) & -6.19 & -6.84 & -7.39 & 29.19 & 9.63 & 3.84 \\
\hline Average (C.S. 23 to 20) & -6.19 & -6.84 & -7.39 & 29.34 & 9.71 & 3.88 \\
\hline St. Deviation & 0.06 & 0.08 & 0.09 & 2.92 & 1.30 & 0.60 \\
\hline
\end{tabular}




\section{Supplemental Information References:}

1. Marty, M.T.; Baldwin, A.J.; Marklund, E.G.; Hochberg, G.K.; Benesch, J.L.Robinson, C.V. (2015) Bayesian deconvolution of mass and ion mobility spectra: from binary interactions to polydisperse ensembles. Anal Chem. 87(8), 4370-6.

2. Kuzmic, P. (1996) Program DYNAFIT for the analysis of enzyme kinetic data: application to HIV proteinase. Anal Biochem. 237(2), 260-73.

3. Ihms, E.C.; Kleckner, I.R.; Gollnick, P.Foster, M.P. (2017) Mechanistic Models Fit to Variable Temperature Calorimetric Data Provide Insights into Cooperativity. Biophys J. 112(7), 13281338. 